\title{
An exploration of the effect of hemodynamic changes due to normal aging on the fNIRS response to semantic processing of words
}

\author{
Mahnoush Amiri ${ }^{1,2}{ }^{*}$, Philippe Pouliot ${ }^{1,3}$, Clément Bonnéry ${ }^{1}$, Paul-Olivier Leclerc ${ }^{2,4}$, Michèle Desjardins ${ }^{1}$, \\ Frédéric Lesage ${ }^{1,3}$ and Yves Joanette ${ }^{2,5}$ \\ ${ }^{1}$ Laboratory of Optical and Molecular Imaging, Biomedical Engineering, Polytechnique Montreal, Montreal, OC, Canada \\ ${ }^{2}$ Laboratory of Neuropsychology of Language, Research Center; Aging Neuroscience, Institut Universitaire de Gériatrie de Montréal, Montreal, OC, Canada \\ ${ }^{3}$ Montreal Heart Institute, Montreal, OC, Canada \\ ${ }^{4}$ Biomedical Engineering Institute, University of Montreal, Montreal, QC, Canada \\ ${ }^{5}$ Faculty of Medicine, University of Montreal, Montreal, QC, Canada
}

\section{Edited by:}

Jessica A. Turner, Georgia State

University, USA

Reviewed by:

Jessica A. Turner, Georgia State University, USA

Blaise Frederick, Harvard Medical

School, USA

*Correspondence:

Mahnoush Amiri, Laboratory of Optical and Molecular Imaging,

Biomedical Engineering, École

Polytechnique de Montréal, CP 6079

succ. Centre-ville, Montreal, OC, H3C

3A7, Canada

e-mail:mahnoush.amiri@polymtl.ca
Like other neuroimaging techniques assessing cerebral blood oxygenation, near-infrared spectroscopy (NIRS) has been applied in many neurocognitive studies. With NIRS, neural activation can be explored indirectly via hemodynamic changes in the imaged region. In studies of aging, changes in baseline physiology and brain anatomy confound NIRS measures seeking to investigate age-related changes in neuronal activity. The field is thus hampered by the complexity of the aging process itself, and statistical inferences from functional data acquired by optical imaging techniques must be interpreted with care. Multimodal integration of NIRS with both structural and baseline physiological assessments is crucial to avoid misinterpreting neuroimaging signals. In this study, a combination of two different optical techniques, anatomical MRI and Arterial Spin Labeling (ASL), was used to investigate age-related changes in activation during a lexical-semantic processing task. Quantitative analysis revealed decreased baseline oxyhemoglobin and cerebral blood flow in the older adults. Using baseline physiology measures as regressors in the investigation of functional concentration changes when doing analyses of variance, we found significant changes in task-induced areas of activity. In the right hemisphere, more significant age-related activity was observed around the junction of the inferior frontal gyrus and inferior precentral sulcus, along with engagement of Wernicke's area. In the left hemisphere, the degree and extent of frontal activation, including the dorsolateral prefrontal cortex and inferior frontal gyrus, differed between age groups. Measuring background physiological differences and using their values as regressors in statistical analyses allowed a more appropriate, age-corrected understanding of the functional differentiations between age groups. Age-corrected baselines are thus essential to investigate which components of the NIRS signal are altered by aging.

Keywords: cognitive aging, language, semantics, functional NIRS, anatomical MRI, baseline physiology, hemodynamic response, ASL

\section{INTRODUCTION}

Given the growing proportion of elderly adults in the population due to increased longevity, studies investigating and promoting healthy cognitive aging are of the utmost importance. By 2050, the number of elderly individuals will be $16 \%$ higher than the number of children and adolescents under 15 years (1). In this context, the number of dementia cases in the aging population is expected to grow exponentially. Prevalence studies in all world regions estimate that 24.3 million people currently have dementia and predict that the number of persons with Alzheimer's disease will double every 20 years, rising to 81.1 million by 2040 (2). This trend supports the importance of characterizing the mechanisms underlying healthy cognitive aging in order to optimize healthy aging and possibly contribute to delaying the manifestations of dementia.
Normal aging is characterized by significant modifications of the brain's anatomy and physiology, which vary depending on the brain region and component (3). The overall volume and weight of the brain decrease with each decade of age but displays regional variability. For example, in a five-year longitudinal study, Raz and colleagues have examined age-related differences in regional brain volume (4). A significant negative correlation between age and volume of the lateral prefrontal cortex, orbitofrontal cortex, and prefrontal white matter was observed. In the temporal association cortices, a more moderate shrinkage with age was also found. These anatomical changes are associated with widening sulci and synaptic loss, but negligible neural loss has been observed.

Age also affects sensory and cognitive abilities but in a heterogeneous fashion, varying with cognitive domain. A first hypothesis to explain this observation is that there is a correlation between 
structural changes and functions. Depending on the cognitive domain (5) and individual characteristics (6), cognitive abilities are affected differently. Among brain functions that are better preserved with aging, older adults have shown a good preservation of semantic word processing and conceptual knowledge organized to depict the relationship between words and stored knowledge of the world. Given that the language-related brain regions (e.g., prefrontal and superior temporal cortices) (7-10) are affected by age $(11,12)$, investigating the mechanisms underlying the relative preservation of language abilities is essential to better understand how the aging brain handles structural and physiological decline.

A major obstacle to these studies is that interindividual variability in cognitive domains increases with aging and this makes it difficult to apply inferences from individual observations over the entire elderly population. To interpret this variability, one can posit that interindividual differences are mainly due to large variations in the anatomical and/or neurophysiological structures underpinning cognitive performance with age (13). An alternative hypothesis is that some older adults compensate for cognitive aging by either adapting compensatory processing procedures by means of an inter- and/or intrahemispheric functional reorganization or changing cognitive strategies $(5,6,14$, $15)$, relying on what has been conceptualized as their cognitive reserve (16). With the aim of revealing cognitive changes associated with age, numerous neuroimaging studies have investigated age-related neurophysiological changes associated with functional brain activities (17-20). Despite overall similarities in basic neuronal activity in young and older adults, older individuals show less activity in some brain regions and/or over-recruitment of other brain regions (21) in response to complex tasks. Overrecruitment can be interpreted as a compensatory mechanism or as an indication of neuronal inefficiency. Thus, the challenge in cognitive aging research is to distinguish between these two mechanisms.

To investigate the complex phenomenon of aging, functional near-infrared spectroscopy (fNIRS) has been used in cognitive neuroscience because of its moderate running costs, portability and potential for examinations in a natural setting (22). This non-invasive imaging technique allows researchers to probe the hemodynamic response evoked by neural activity in the first centimeters of cortical tissues. By emitting near-infrared light (650$950 \mathrm{~nm}$ ) through the scalp and measuring the photons attenuated by absorbing compounds primarily composed of oxy- and deoxygenated hemoglobins ( $\mathrm{HbO}_{2}$ and $\mathrm{HbR}$, respectively), estimates of neural activation can be recovered $(23,24)$. One advantage of fNIRS measures over the blood-oxygen level dependent (BOLD) signal obtained from functional magnetic resonance imaging (fMRI) is its ability to measure oxygenation level. However, in hemodynamic-based functional neuroimaging techniques, such as fMRI and fNIRS, neural activity is measured indirectly through neurovascular coupling as a function of changes in cerebral blood flow (CBF), blood volume, and oxygenation (25). Signals are therefore subject to interpretation difficulties due to the ambiguous interaction of the neurophysiology and vasculature underpinning the hemodynamic response (26-29). Thus, changes in measured activation response are related not only to neuronal activity but also to modifications of the underlying physiology with age. There is evidence from the literature that global $\mathrm{CBF}$ decreases with age, while the cerebral metabolic rate of oxygenation $\left(\mathrm{CMRO}_{2}\right)$ increases $(13,19,30)$, and that microvascular capacity in response to strong demand for oxygenation also declines (17). It is therefore essential for studies to consider these confounding factors if they aim to distinguish the observed physiological changes with age from the underlying neuronal activation in response to a cognitive stimulus.

Other methodological difficulties specific to the NIRS signal are partial volume effects (24) and tissue optical properties that change with age $(31,32)$. The age-related changes in tissue properties and capillary circulation in the skin (33) and how these changes interact with light propagation in the head may bias NIRS measurements when young and elderly individuals are compared. Time-resolved spectroscopy (TRS) systems provide measure of optical properties of cerebral tissues with the ability to distinguish between superficial layers [skin, skull, and cerebrospinal fluid (CSF)] and brain tissue. Thus, intra- and extracerebral hemoglobin concentrations can be determined for each individual separately (34).

The aim of the present study was to assess the physiological and functional changes that occur in parts of the language processing network during normal aging by means of a lexical-semantic decision task and two imaging techniques: anatomical and blood perfusion (arterial spin labeling; ASL) MRI and fNIRS, as well as time-domain optical imaging TRS. By integrating each individual's baseline CBF, oxy- and deoxyhemoglobin concentrations, and structural characteristics, obtained with ASL-MRI, TRS, and anatomical MRI, respectively, with the functional hemodynamic responses from NIRS, the goal of this study was to investigate the effect of intrinsic interindividual variability on the hemodynamic responses measured. Specifically, we hypothesized that each individual's baseline physiology, reflecting his or her neurovascular health, was related to the preservation of semantic memory and cognitive performance. We also hypothesized that higher levels of $\mathrm{CBF}$ and oxygen saturation $\left(\mathrm{SatO}_{2}\right)$ from TRS measurements should account for the percentage changes of $\left[\mathrm{HbO}_{2}\right]$ and $[\mathrm{HbR}]$ in response to our lexical-semantic decision task. Controlling for these age-related factors is crucial if one wishes to distinguish the presumed age-related neurofunctional reorganization of the brain for cognitive ability, such as the semantic processing of words, from the basic neurophysiological changes linked to the aging brain's hemodynamics.

\section{MATERIALS AND METHODS PARTICIPANTS AND PROTOCOL}

In this study, 46 healthy French-speaking individuals divided into two groups of elderly people $(n=23)$, aged $65-75$ (mean age $=69.6 \pm 4.1$ ), and young people $(n=23$ ), aged 20-35 (mean age $=23.4 \pm 2.7$ ), were recruited. Because language knowledge is embedded in the social and cultural context, we restricted our participants to French speakers from Quebec. The elderly cohort was chosen from this specific age bracket because of the delicate transition to old age (>65) and the increased prevalence of cognitive decline (from 4.97 to $24.19 \%$ ) after the age of 80 (35). The study was approved by the ethics committee of the Institut universitaire 
de gériatrie de Montréal (IUGM) and all participants gave their written consent. Exclusion criteria were claustrophobia, hypertension or any cardiovascular disease, smoking, thyroid dysfunction, diabetes, taking any medication known to be vasoactive, as well as psychiatric or neurological illness. Participants were all righthanded according to the Edinburgh Handedness Inventory (36, 37). For the measurement of baseline cerebral blood perfusion, they were also asked to abstain from drinking coffee the day of acquisition $(38,39)$.

Participants were screened for their level of cognitive performance by standardized cognitive assessments including the Trail Making Test A/B (40), the Montreal Cognitive Assessment (MoCA; (41), and five subtests of the short-form Wechsler Adult Intelligence Scale (WAIS-III; (42-44), namely Vocabulary, Block Design, Similarities, Matrix Reasoning, and Direct and Inverse Digit Spans. In this way, it was possible to exclude those with mild cognitive decline according to age-corrected norms. These tasks assess phonological short-term memory storage as well as processing capacities and evaluate general intellectual ability, planning, visual exploration, attention, mental flexibility, and verbal inhibition.

The activation task represents a robust, well-studied lexicalsemantic task: lexical decision (45). Stimuli were chosen from the specific categories of non-action words (nouns) denoting non-living objects in order to isolate the peripheral effects in networks associated with semantic processing. Words generated from a French lexical database (OMNILEX database from the Cognitive Psychology of Language Laboratory, University of Ottawa, Canada) were matched according to their lexical frequency, grammatical category (nouns), age of acquisition, orthographic structure, and length in letters. It is important to note that, in visual lexical decision tasks, word length affects reaction time (RT), with stable RTs for words four to six letters long (46). Concreteness of the words (abstract vs. concrete) was manipulated by the imageability index on a scale of 1-7 to investigate the effect of word imageability within a lexical decision test $(n=60$ for each category). Pseudo-words were then created from the real words $(n=120)$ by changing two consonants. All items (words and pseudo-words) were then matched by bigram frequency and length in letters (Lexique database, Paris Descartes University, France). A pilot study of 15 young adults was done prior to the main study to eliminate outliers within each category. Participants were presented with words and pseudo-words on the screen and were instructed to answer whether or not the letter string constituted a real word. Each trial started with a fixation point $(+)$ that appeared at the center of the screen and was followed by the stimulus. A blank screen provided time to answer with a yes/no button on the computer keyboard. The task was executed using E-prime software (version 2.1), which also recorded the RTs and correct responses.

The paradigm was designed in an event-related (ER) fashion. The ER design presented each stimulus at a specific time, allowing the investigation of the evoked hemodynamic response delayed by $2-3$ s from stimulus-induced neuronal activity (47). Stimuli from different categories (e.g., experimental conditions; word vs. pseudo-word.) were presented in a random intermixed order for 4-11 s (Figure 1).

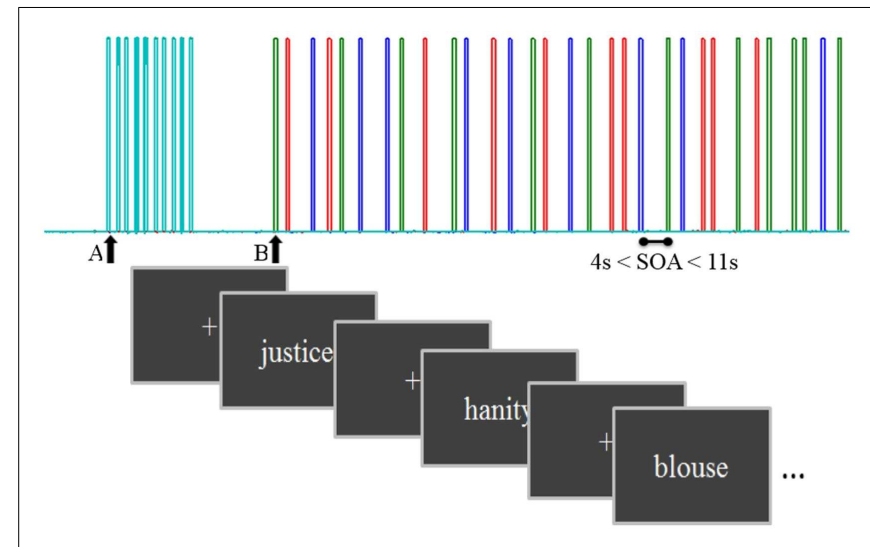

FIGURE 1 | A schema of the task diagram with inter stimulus interval $=1.36 \mathrm{~s}$ and stimulus onset asynchrony from 4 to $11 \mathrm{~s}$. Triggers from the computer presenting the task were sent to the NIRS computer after synchronization: $A$, start control task and B, start main task. Each color bar represents a different condition: concrete, abstract, and pseudo-words.

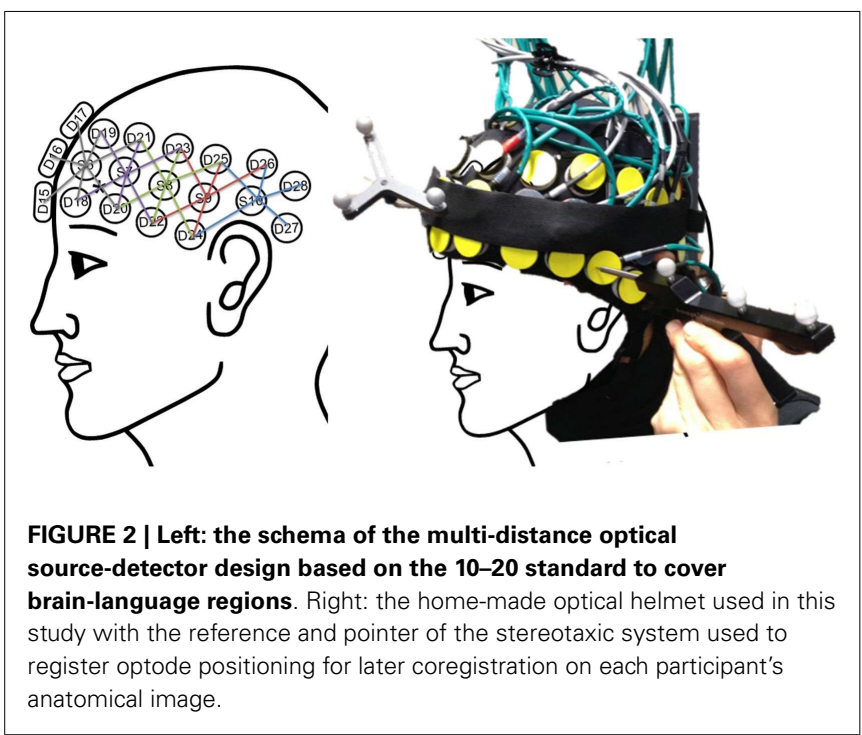

\section{DIFFUSE OPTICAL MEASUREMENTS} Near-infrared spectroscopy

Task-induced changes in optical intensity were measured with a 32-channel continuous wave NIRS instrument (TechEn CW6) with a sampling rate of $25 \mathrm{~Hz}$. TechEn uses two continuous frequency modulated wavelengths at 830 and $690 \mathrm{~nm}$, within a wavelength range where $\mathrm{HbO}_{2}$ and $\mathrm{HbR}$ are the dominant light absorbers. Using two different wavelengths, we were able to assess the changes in hemoglobin concentration from absorption coefficients $\left(\mu_{\mathrm{a}}\right)$ by measuring light attenuation (modified Beer-Lambert law; (23). In this study, we used two patches of 29 channels (a combination of 5 sources and 14 detectors) for each hemisphere, covering the entire frontal and temporal regions of the cortex (Figure 2 ). To reliably position the posterior edge of the optical helmet, we used the electrode positions $\mathrm{Fp}_{0}$ and inion as references according to the 10-20 EEG system. 


\section{Time-resolved spectroscopy}

A TRS system using four pulsed lasers with wavelengths of 690,750 , 800 , and $850 \mathrm{~nm}$, temporally multiplexed, illuminated the participant's forehead. Four detectors at distances of 10, 15, 25, and $30 \mathrm{~mm}$ from the point of illumination collected the backscattered light and were then focused on the detection surface of photoncounting avalanche photodiodes with a $20 \times$ microscope objective. The experiment took place in a dark room to reduce the noise on the single-photon counter detectors.

The measurements obtained were fit to a double-layer analytical model (34). Thus, the head was modeled as a heterogeneous medium, with the first layer consisting of skin, skull, and CSF and the second layer including both gray and white matter. The model yielded absolute estimates of the optical properties [absorption $\left(\mu_{\mathrm{a}}\right)$ and scattering $\left(\mu_{\mathrm{s}}\right)$ coefficients] in each layer.

\section{MRI ACQUISITION}

Anatomical MR images were obtained on a 3T Siemens Trio MRI (Siemens Medical Solutions, Erlangen, Germany) using a 32-channel receive-only head coil at the Unité de Neuroimagerie Fonctionnelle of the IUGM. A volumetric Magnetization Prepared Rapid Gradient Echo (MPRAGE) sequence was used to acquire a high-resolution $\mathrm{T} 1$-weighted $3 \mathrm{D}$ anatomical image, using the following parameters: $\mathrm{TR}=2.3 \mathrm{~s}, \mathrm{TE}=2.91 \mathrm{~ms}, \mathrm{TI}=900 \mathrm{~ms}$, flip angle $=9^{\circ}$, FOV $=240 \times 256$, voxel size $=1 \times 1 \times 1 \mathrm{~mm}^{3}$. This sequence was followed by an ASL sequence at rest, without sensory deprivation. The imaging sequence was a PICORE labeling geometry (20) and Q2TIPS tag duration control (48) to quantify the baseline CBF $\left(\mathrm{CBF}_{0}\right.$; (49). A post-label delay of $900 \mathrm{~ms}$ and label duration of $1500 \mathrm{~ms}$ were used, with repetition time (TR) and echo time (TE) of $3 \mathrm{~s}$ and $20 \mathrm{~ms}$, respectively. The ASL signal is evoked by the local magnetization differences following the diffusion of the magnetically labeled blood to quantitatively measure blood perfusion. A single $\mathrm{M}_{0}$ scan was also acquired to compute the blood perfusion parameters. This acquisition was done with the same parameters as the ASL sequence except for the TR, which was set to be very long ( $10 \mathrm{~s}$ ) to yield a measurement of the fully relaxed magnetization. The whole acquisition including the MPRAGE took approximately $20 \mathrm{~min}$.

\section{COREGISTRATION}

A stereotaxic system (Brainsight, Rogue Research Inc.) was used to align anatomical images from each individual's MRI and the patch holding the optical fibers. The registered positions of each optode were then mapped into normalized brain coordinates from Montreal Neurological Institute (MNI) template for group analysis.

\section{DATA ANALYSIS}

\section{BEHAVIORAL AND TASK PERFORMANCE}

$Z$-scores for each cognitive test were calculated from the normative reference data available for different age groups. Only participants whose results were above the normal guideline were kept for further analysis. The RTs and the accuracy of responses to the lexical-semantic task were analyzed using SPSS (IBM, New York, USA). A two-way repeated measures analysis of variance (ANOVA) was applied to RTs for correct answers as a dependent variable with the factors of age (young, elderly) and condition (word, pseudo-word).

\section{NIRS DATA SIGNAL PROCESSING AND STATISTICAL ANALYSIS}

Both signal processing (heart rate regression, intensity to concentration conversion, normalization, and smoothing) and statistical analysis (general linear model, GLM) were performed using an SPM8-compatible toolbox made in-house (50) based on NIRS-SPM v3.2; NIRS10.

Changes in optical density, $\triangle \mathrm{OD}$, were computed from emitted and received photon fluence $\Phi$ :

$$
\Delta \mathrm{OD}(t, \lambda)=-\ln \left(\frac{\Phi(t, \lambda)}{\Phi_{0}(t, \lambda)}\right)
$$

A heart rate analysis was done to eliminate channels without physiological signals. A coregistration of the source-detector positions on the MNI's MRI template was done to ensure coherent optode positioning for group analysis. Optical signals were then transformed into hemoglobin concentrations $C_{\mathrm{HbO} 2}$ and $C_{\mathrm{HbR}}$, applying the modified Beer-Lambert law with

$$
\left[\begin{array}{l}
C_{\mathrm{HbO} 2}(t) \\
C_{\mathrm{HbR}}(t)
\end{array}\right]=\left[\begin{array}{ll}
\varepsilon_{\mathrm{HbO} 2}^{\lambda_{1}} & \varepsilon_{\mathrm{HbO} 2}^{\lambda_{2}} \\
\varepsilon_{\mathrm{HbR}}^{\lambda_{1}} & \varepsilon_{\mathrm{HbR}}^{\lambda_{2}}
\end{array}\right]^{-1}\left[\begin{array}{l}
\Delta \mathrm{OD}\left(t, \lambda_{1}\right) /\left(d \cdot \ell_{\mathrm{DPF}}\left(\lambda_{1}\right)\right) \\
\Delta \mathrm{OD}\left(t, \lambda_{2}\right) /\left(d \cdot \ell_{\mathrm{DPF}}\left(\lambda_{2}\right)\right)
\end{array}\right]
$$

where $\lambda_{\mathrm{DPF}}$ is the differential path-length factor accounting for the random photon trajectory between each source and detector (32).

Hemoglobin concentration changes were filtered with a Gaussian kernel (1.5 s FWHM) and high pass filtered by a second-order Butterworth filter with a cutoff frequency of $0.01 \mathrm{~Hz}$. The significance of each effect of interest (abstract, concrete, and pseudoword) was determined using the theory of Gaussian fields (47). A GLM was fit using a canonical hemodynamic response function (HRF). Contrasts over sessions (intrasubject) were analyzed using a fixed effects model, while testing for contrasts in the intersubject analysis was done by estimating the ratio of the random effects variance to the fixed effects variance. An expected Euler correction based on Lipschitz-Killing curvatures was applied to the threshold on the $\mathrm{HbR} / \mathrm{HbO}_{2} t$-statistic images to account for the spatial correlation. The GLM method was based on the precoloring method of NIRS-SPM toolbox (51) for noise treatment.

\section{TRS DATA}

To determine the value of the background absorption and scattering coefficients of the brain, a reflectance curve was fit for each source-detector pair of the time-domain system (34). The curve-fitting procedure was done by a non-linear optimization MATLAB function (Isqcurvefit) with fit parameters of absorption and reduced scattering coefficient ( $\mu_{\mathrm{a}}$ and $\mu_{\mathrm{s}}$, respectively) and amplitude to the theoretical temporal point spread function (TPSF). We applied the appropriate analytical model to fit the reflectance curve. This model was validated by applying a Monte Carlo simulation and with a priori information about the thickness of the first layer, including skin, skull, and CSF, obtained from the segmented anatomical MR images (using SPM8). With a high-resolution T1-weighted anatomical image, the maximum 
errors on the hemoglobin concentrations were expected to be no more than $15 \%$ (34).

To determine hemoglobin concentrations from optical parameters, we assumed that oxy- and deoxyhemoglobin and water were the dominant absorbers between the 690 and $850 \mathrm{~nm}$ wavelengths. The linear system describing the relationship between the extinction coefficient $\varepsilon(\lambda)$ (taken from the literature) and the absorption coefficient $\mu_{\mathrm{a}}(\lambda)$ (calculated from TRS measures) is given by

$$
\begin{gathered}
\mu_{\mathrm{a}}(\lambda)=2.303 \cdot \varepsilon(\lambda) \cdot C \\
{\left[\begin{array}{c}
\mu_{\mathrm{a}}\left(\lambda_{1}\right) \\
\mu_{\mathrm{a}}\left(\lambda_{2}\right) \\
\mu_{\mathrm{a}}\left(\lambda_{3}\right) \\
\mu_{\mathrm{a}}\left(\lambda_{4}\right)
\end{array}\right]=\left[\begin{array}{lll}
\varepsilon_{\mathrm{HbO}_{2}}\left(\lambda_{1}\right) & \varepsilon_{\mathrm{HbR}}\left(\lambda_{1}\right) & \varepsilon_{\mathrm{H}_{2} \mathrm{O}}\left(\lambda_{1}\right) \\
\varepsilon_{\mathrm{HbO}_{2}}\left(\lambda_{2}\right) & \varepsilon_{\mathrm{HbR}}\left(\lambda_{2}\right) & \varepsilon_{\mathrm{H}_{2} \mathrm{O}}\left(\lambda_{2}\right) \\
\varepsilon_{\mathrm{HbO}_{2}}\left(\lambda_{3}\right) & \varepsilon_{\mathrm{HbR}}\left(\lambda_{3}\right) & \varepsilon_{\mathrm{H}_{2} \mathrm{O}}\left(\lambda_{3}\right) \\
\varepsilon_{\mathrm{HbO}_{2}}\left(\lambda_{4}\right) & \varepsilon_{\mathrm{HbR}}\left(\lambda_{4}\right) & \varepsilon_{\mathrm{H}_{2} \mathrm{O}}\left(\lambda_{4}\right)
\end{array}\right]\left[\begin{array}{c}
C_{\mathrm{HbO}_{2}} \\
C_{\mathrm{HbR}} \\
C_{\mathrm{H}_{2} \mathrm{O}}
\end{array}\right]}
\end{gathered}
$$

We also assumed that biological tissues contained $70 \%$ water, reducing the above system to four equations with two unknowns. A pseudo-inversion of the equation with a least-square fit provided $C$, the hemoglobin concentration.

\section{ANATOMICAL MRI}

Coregistration: The anatomical images served two purposes in this study. First, at the individual level, we normalized the anatomical images to the MNI space including the subject's fiducial coordinates. Then, to achieve better spatial resolution for fNIRS analysis, we projected the optodes' positioning coordinates, collected from the Brainsight 3D camera, on the cortex (Figure 3). For group analysis, we needed to transform all images to the MNI template. These steps were performed using an in-house version of the algorithm of NIRS_SPM

\section{ASL DATA}

The absolute CBF was measured in arbitrary units by the constant component of an ASL scan $\left(\mathrm{ASL}_{0}\right)$ using the standard quantitative approach described by Wong et al. (52). This value was then converted to physiologically relevant units ( $\mathrm{mL}$ blood/100 $\mathrm{g}$ tissue per minute) using a general kinetic model fit to the ASL signal $(20,49)$. This model defines a relationship between the measured signal and $\mathrm{CBF}_{0}$ assuming blood longitudinal relaxation time $\mathrm{TI}$ and fully relaxed magnetization $\mathrm{M}_{0}$ are known

$$
\mathrm{CBF}_{0}=\frac{\mathrm{ASL}_{0}}{6 \times 10^{6} \cdot 2 \cdot \mathrm{TI} 1 \cdot \exp (-\mathrm{TI} 2 / \mathrm{T} 1 b) \cdot M_{0 \mathrm{~b}}}
$$

where $\mathrm{TI} 1=1400 \mathrm{~ms}$, TI $2=2000 \mathrm{~ms}$, and $\mathrm{T} 1 \mathrm{~b}=1932 \mathrm{~ms}$ at $3 \mathrm{~T}$ and the factor $6 \times 10^{6}$ converts the units for $\mathrm{CBF}_{0}$ to $\mathrm{mL} / \mathrm{min} / 100 \mathrm{~g}$. The value for $M_{0 \mathrm{~b}}$, the fully relaxed blood magnetization, was calibrated using that of the white matter measured in the $\mathrm{M}_{0} \operatorname{scan}(52)$ :

$$
M_{0 \mathrm{~b}}=M_{0 \mathrm{WM}} \cdot \frac{1}{\lambda} \cdot \exp \left(\mathrm{TE} \cdot\left(\frac{1}{T_{2 \mathrm{WM}}}-\frac{1}{T_{2 \mathrm{~b}}}\right)\right)
$$

with $M_{0 \mathrm{WM}}$ the average value of the $M_{0}$ scan in a region of interest (ROI) selected from the segmented white matter, the brain-blood partition coefficient for water $\lambda=0.9 \mathrm{~mL} / \mathrm{g}$ (53), $\mathrm{TE}=12 \mathrm{~ms}$, $T_{2 \mathrm{WM}}=70 \mathrm{~ms}$, and $T_{2 \mathrm{~b}}=275 \mathrm{~ms}$ at $3 \mathrm{~T}$. The blood flow measurement was then regressed against the functional NIRS data to evaluate its impact.

\section{RESULTS}

\section{NEUROPSYCHOLOGICAL PERFORMANCE}

There was no difference $(p>0.05)$ between the two age groups' mean years of education (older $=16 \pm 2.33$ and younger $=16.95 \pm 1.78)$. Both age groups were also matched for sex and consisted of 15 women and 8 men. They were compared on the neuropsychological measures of memory, vocabulary, and executive functions described earlier. The older adults performed worse on a number of subtests evaluating executive functions, but consistently with our hypothesis, the results of the vocabulary test showed no significant difference between the two groups (Table 1). Since responding correctly to the lexical-semantic decision task does not require planning or strategic changing skills, we expected these differences to have no impact on results.

\section{TASK PERFORMANCE}

Both groups performed equally accurately across conditions except on pseudo-words derived from concrete words $[\mathrm{F}(1$,

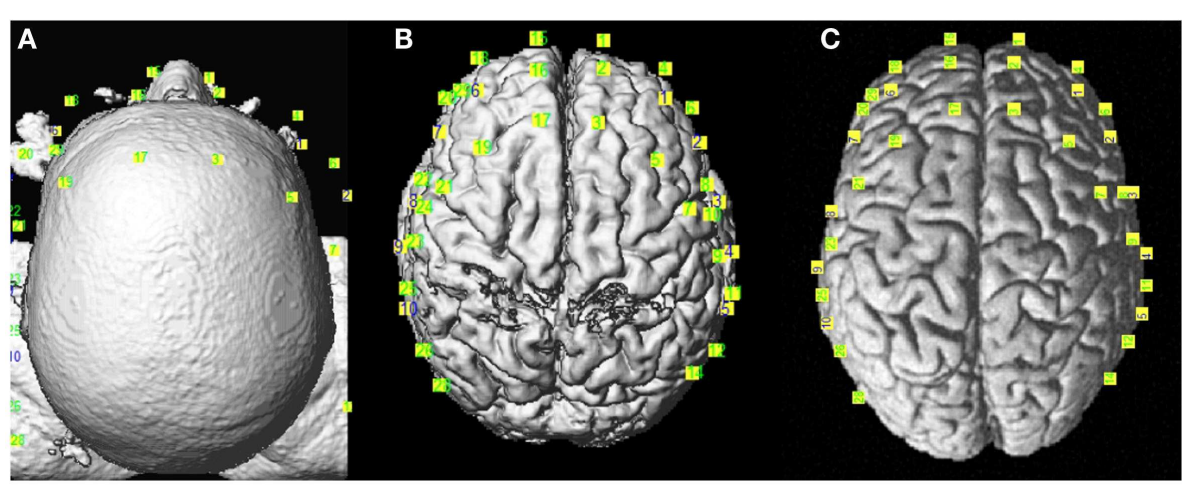

FIGURE 3 | Coregistration of the optodes' positions from Brainsight@over the reconstructed anatomical images. (A) Real, (B) MNI subject, and (C) MNI template spaces. 
Table 1 | Demographic variables and cognitive characteristics.

\begin{tabular}{|c|c|c|c|c|c|}
\hline & Variable & $\begin{array}{l}\text { Young ( } n=23 \text { ) } \\
\text { mean (SD) }\end{array}$ & $\begin{array}{l}\text { Older }(n=23) \\
\text { mean (SD) }\end{array}$ & $F$-test ( $p$-value) & $t$-test ( $p$-value) \\
\hline & MoCA & $29.23(1.30)$ & $27.27(2.47)$ & 0.0054 & $0.0037^{*}$ \\
\hline \multirow[t]{5}{*}{ WAIS } & Vocabulary & 43.65 (7.68) & 37.64 (14.75) & 0.027 & 0.15 \\
\hline & Similarity & $21.23(5.08)$ & 17.73 (3.92) & 0.32 & $0.008^{*}$ \\
\hline & Block design & $61.82(3.15)$ & 35.27 (7.93) & 0.0002 & $0.000 * *$ \\
\hline & Matrix & $23.12(2.87)$ & $15.91(5.70)$ & 0.007 & $0.000 * *$ \\
\hline & Digit spans & 19.06 (4.34) & 18.64 (3.99) & 0.72 & 0.15 \\
\hline \multirow[t]{3}{*}{ Hayling } & Automatic & $6.94(0.24)$ & $6.91(0.29)$ & 0.3 & 0.65 \\
\hline & Inhibition & 5.47 (1.18) & 4.82 (1.65) & 0.1 & 0.15 \\
\hline & Final score & 19.29 (1.61) & 17.5 (2.70) & 0.47 & 0.12 \\
\hline
\end{tabular}

Results from neuropsychological batteries by age group. MoCA, Montreal Cognitive Assessment; WAIS, Wechsler Adult Intelligent Scale; Hayling, test for inhibitory control. ${ }^{*} p<0.05,{ }^{* *} p<0.0001$.

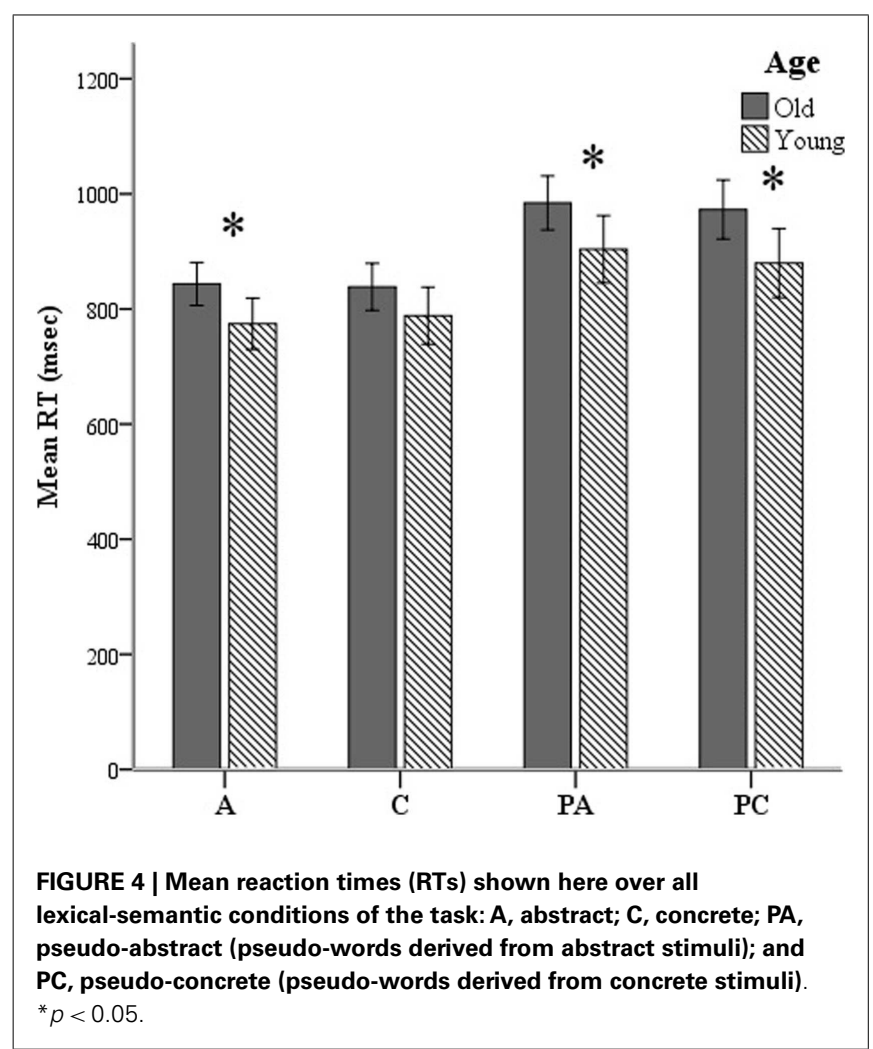

$55)=6.1, p=0.017]$. Young participants were faster in all conditions except for concrete words. We applied a two-standarddeviation cutoff on the RTs of correct responses. RTs for correct trials are presented in Figure 4. Results from two 2-way ANOVAs showed no age $\times$ lexicality $[\mathrm{F}(1,176)=0.621, p>0.05]$ or age $\times$ condition $[\mathrm{F}(1,176)=0.275, p>0.05]$ interactions. There was a simple effect of lexicality $[\mathrm{F}(1,179)=11.4, p=0.001]$, irrespective of age.

\section{TIME-RESOLVED SPECTROSCOPY}

We calculated the absolute oxy- and deoxyhemoglobin concentrations ( $\left[\mathrm{HbO}_{2}\right]$ and $[\mathrm{HbR}]$, respectively) as well as oxygen
Table 2 | Results from TRS measurements.

\begin{tabular}{|c|c|c|c|c|}
\hline & \multicolumn{2}{|c|}{ LH } & \multicolumn{2}{|c|}{$\mathbf{R H}$} \\
\hline & Old & Young & Old & Young \\
\hline$[\mathrm{HbO} 2]$ & $40.9( \pm 1.7)$ & $49.1( \pm 2.1)$ & $42.6( \pm 1.8)$ & $46.5( \pm 1.3)$ \\
\hline$t$-Test & \multicolumn{2}{|c|}{$0.002^{* *}$} & \multicolumn{2}{|c|}{$0.039^{*}$} \\
\hline$[\mathrm{HbR}]$ & $25.8( \pm 1.1)$ & $28.2(1.0)$ & $25.9( \pm 1.1)$ & $25.6( \pm 1.0)$ \\
\hline$t$-Test & \multicolumn{2}{|c|}{0.056} & \multicolumn{2}{|c|}{0.428} \\
\hline SatO2 & $61.2( \pm 0.7)$ & $63.3( \pm 0.9)$ & $62.2( \pm 0.7)$ & $64.6( \pm 1.0)$ \\
\hline$t$-Test & \multicolumn{2}{|c|}{$0.045^{*}$} & \multicolumn{2}{|c|}{$0.029 *$} \\
\hline
\end{tabular}

Oxy-and deoxyhemoglobin concentrations and oxygen saturation calculated in both hemispheres from TRS measures in micromoles, ${ }^{*} p<0.05,{ }^{*} p<0.001$.

saturation $\left(\mathrm{SatO}_{2}\right)$ in both right and left prefrontal lobes covered by our four-channel TRS patch. Considerable intersubject variability was observed in the measures of hemoglobin concentrations, as previously reported in the literature (34). Group mean comparisons were inspected for the homogeneity of variance assumption. When the variance test of homogeneity was significant, the $p$-value of the unequal variance for one-tailed $t$-tests was reported. TRS measures of right and left frontal areas were analyzed separately. Older adults showed a resting $\left[\mathrm{HbO}_{2}\right]$ and $[\mathrm{HbT}]$ $\left(\mathrm{HbT}=\mathrm{HbO}_{2}+\mathrm{HbR}\right)$ decrease in the left hemisphere compared to the right and an overall reduced $\left[\mathrm{HbO}_{2}\right]$ compared to young adults (Table 2). A one-tailed comparison revealed a decrease in $\mathrm{SatO}_{2}$ in both left and right prefrontal lobes for the elderly group ( $p=0.045$ and 0.029 , respectively). Because we observed a different trend in hemispheric changes in the measured hemoglobin concentrations across age, we applied a two-way ANOVA to investigate the effect of the baseline physiology of aging and laterality. The results showed no significant interaction between age and laterality.

\section{RESTING-STATE CBF}

Analysis of tagged ASL images revealed different group averages over the segmented white and gray matter anatomical images 
applied as explicit masks. Mean baseline CBF calibrated with the use of individual voxel values of the $M_{0}$ sequence was computed for both age groups and a significant difference was observed for global $(p=0.001)$ and gray matter $(p=0.02)$ blood perfusion (Figure 5). To investigate regional effects, we calculated mean $\mathrm{CBF}$ within regions of interest (ROIs) defined by the optical helmet. Temporal and frontal ROIs were created by applying a $35 \mathrm{~mm}$ diameter disk around optical channels covering the temporal and frontal regions. At rest, older adults had significantly lower blood flow $(p=0.01)$ in both temporal and frontal lobes than their younger counterparts.

\section{FUNCTIONAL OPTICAL RECORDINGS}

Stimulus-dependent activation of all 58 channels was measured within the areas covered by the optodes. Significant changes were defined at $p$-values of less than 0.05 . The activation map was then obtained via interpolation of the beta values calculated from the GLM model over the localized optodes coregistered on the MNI template, although a lack of spatial resolution made it difficult to identify activation areas with any precision.

The regions of activation for group average, obtained from the intersection of individuals' activation maps, were impacted by variability induced in the positioning of optodes. Thus, a smaller group-level significant activation map was obtained, although the pattern of activation followed the same language network areas at the individual level. Brain regions activated by the lexical-semantic task were partially different for word and pseudo-word stimuli. In response to semantic word processing, a decrease in [HbR] concentration was observed in the elderly adults group in the left frontal region, at the intersection of the right inferior frontal gyrus (IFG) and the superior temporal gyrus (STG). In young adults,

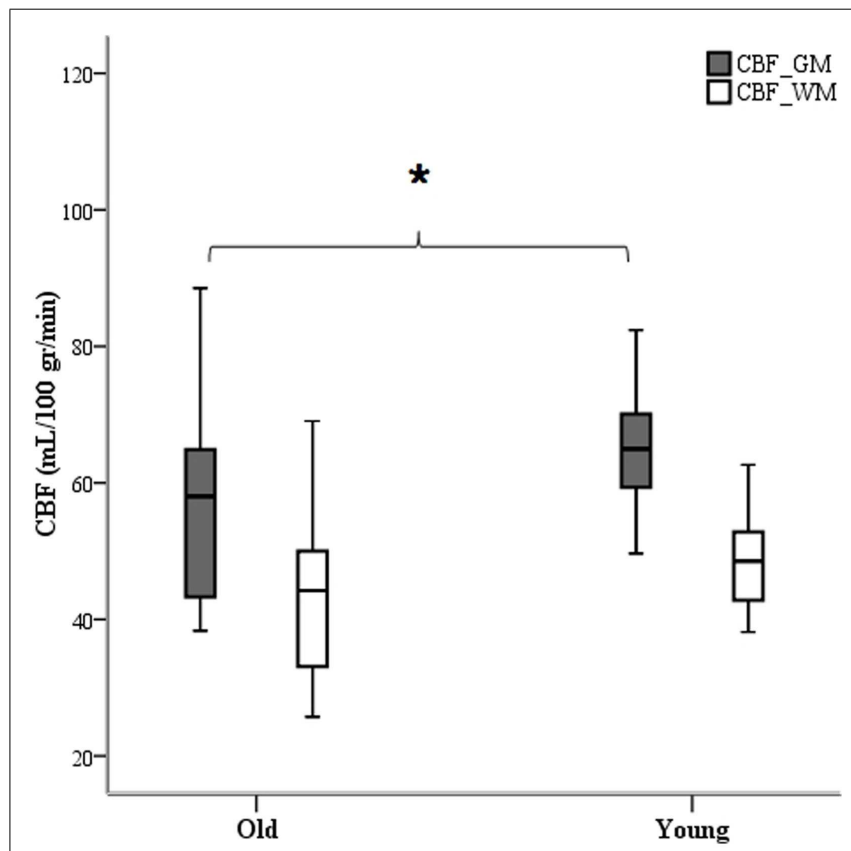

FIGURE 5 | White and gray matter segmented images as ROI masks were used to calculate mean CBF. Only gray matter blood perfusion yielded a difference between age group averages. ${ }^{*} p<0.05$. pseudo-word stimuli generated diminished $[\mathrm{HbR}]$ and increased $\left[\mathrm{HbO}_{2}\right]$ in the left IFG but an inverse response (decreased $\left[\mathrm{HbO}_{2}\right]$ and increased $[\mathrm{HbR}]$ ) in the left inferior temporal (IT) and frontal lobes. In contrast to elderly participants, activated areas remained in the temporal sulci for other types of stimuli (concrete and abstract) but again in an inverse fashion.

An ANOVA for the main effect of age depicted significant $\left[\mathrm{HbO}_{2}\right]$ and $[\mathrm{HbR}]$ changes in both right and left hemispheres when older and younger adults were compared. Activation differences were mainly found in the bilateral dorsolateral prefrontal cortex (DLPFC) and IFG, and right posterior middle temporal and occipitotemporal gyri. Younger participants showed increased $[\mathrm{HbR}]$ and decreased $\left[\mathrm{HbO}_{2}\right]$ in the DLPFC and IFG in response to the semantic processing task (so-called inverse response). Conversely, pseudo-words led to a significant right ventral anterior premotor cortex decrease [HbR], which could be interpreted as an effort to analyze the stimulus by covert reading.

\section{TRS regressors}

Taking into account the measures of baseline physiology from the TRS system by including individual measures as regressors, we investigated their contribution to the observed age difference in $\left[\mathrm{HbO}_{2}\right]$ and $[\mathrm{HbR}]$ stimulus-dependent changes. In the right hemisphere, the main effect of age faded significantly in the frontal lobe for both $\left[\mathrm{HbO}_{2}\right]$ and $[\mathrm{HbR}]$, and $[\mathrm{HbR}]$ seemed to become more significant at the intersection of the IFG, STG, and caudal border of the anterior central gyrus (BA43) (Figure 6). In the same fashion, a post hoc ANOVA on the effect of age on lexicality (pseudo-words), revealed significant [HbR] differences in right BA43. However, there was no such effect on total hemoglobin concentration [HbT] differences with regressors, which could suggest that the blood supply alters with age, if we use [HbT] as an estimate of cerebral blood volume. In the left hemisphere, there was an age difference in the frontal lobe (Figure 7), with no effect of TRS regressors. An interaction between age and condition was present only at the $[\mathrm{HbR}]$ level, with changes found in the IFG. A post hoc analysis revealed an effect of age on pseudo-word processing in the DLPFC and IFG. In the left hemisphere, we did not find any significant differences in the temporal regions.

\section{CORRELATION ANALYSES}

A correlation coefficient was calculated to examine the associations between age, performance and baseline physiology (ASL and TRS measures). Here, we sought relationships between RT and physiological measures while controlling for the effects of age and performance. The partial correlation coefficient between RT and $\left[\mathrm{HbO}_{2}\right],[\mathrm{HbR}], \mathrm{SatO}_{2}$, and $\mathrm{CBF}$ was calculated by adjusting for age and performance scores. We presumed that both variables of correlation were linearly related to age and performance on the neuropsychological tests.

Inspection of the correlations between RT and CBF measures revealed no significant relationship. Pearson's coefficient of correlation between $\mathrm{RT}$ and $\left[\mathrm{HbO}_{2}\right],[\mathrm{HbR}]$ and $\mathrm{SatO}_{2}$ dropped significantly once we removed the effect of age (from $r(42)=0.35$ to $r(40)=0.06)$. It is interesting to note that, even though there were no significant correlations between the variables under investigation, the variations tended to move in opposite directions when younger and older adults were compared (see Figure 8). 

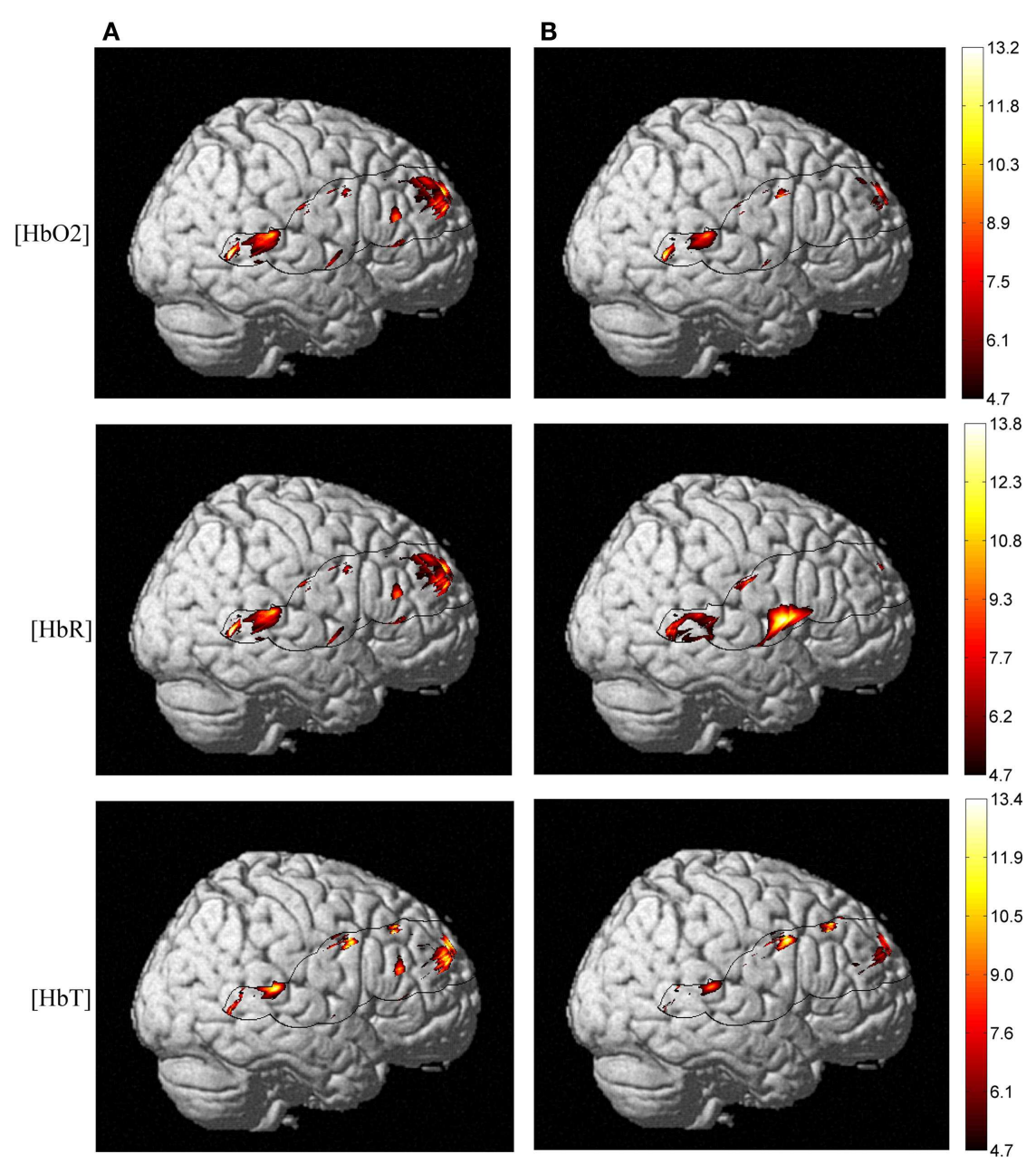

FIGURE 6 | NIRS activation maps of the hemoglobin concentrations for the main effect of age. With TRS measures of baseline hemoglobin concentrations regressed against stimulus-dependent activation, we observed a different pattern of posterior-inferior alteration as an effect of age. But this pattern is more
The tendency graphs revealed that slower responding elderly participants had slightly elevated baseline $\left[\mathrm{HbO}_{2}\right],[\mathrm{HbR}]$, and $\mathrm{SatO}_{2}$, whereas younger individuals showed the opposite pattern (i.e., slower respondents had lower baseline levels).

\section{DISCUSSION}

The goal of this study was to evaluate the validity of the assumption that, when different age groups are compared, the hemodynamic response is a direct indicator of neuronal activity in response to a cognitive stimulus. The main result showed that, when each participant's baseline physiology is taken into account, the degree and extent of neural activity varied significantly in the right hemisphere - an observation that could change the interpretation of less asymmetrical language-related neural engagement. The present study supports the reliability of single-word processing studies using fNIRS while urging caution in the interpretation of functional signals. RTs and accuracy on the lexical-semantic task showed the presence of a lexicality effect for both age groups. pronounced at the $\left[\mathrm{HbO}_{2}\right]$ and $[\mathrm{HbR}]$ level and not for $[\mathrm{HbT}]$, which is an estimate of the cerebral blood volume. Panel (A) shows $\Delta[\mathrm{Hb}]$ age differences without taking into account baseline physiology measures and panel (B) depicts activation differences once applying TRS regressors into ANOVA.
However, a different pattern of brain activation was found for young and older participants. We observed that searching for semantic knowledge while processing words vs. pseudo-words in the lexical-semantic task engaged largely overlapping brain regions in the left hemisphere, including the posterior temporal gyri, which is consistent with the notion that activity in the left temporal regions is linked to the verbal abilities of word retrieval rather than the lexical class to which the stimulus belongs (54).

A right frontal [HbT] difference between the young and older samples could be in line with findings from TRS measures for lower oxygen saturation in the elderly group. In response to neural activity and to compensate for reduced baseline $\mathrm{HbO}_{2}$ concentrations and $\mathrm{CBF}$, older adults may need greater blood volume in their compensatory networks. Thus, controlling for baseline physiology is expected to make the interpretation of results more reliable.

The presence of right DLPFC, frontotemporal cortex, occipitotemporal and angular gyri [homolog to areas known as the visual 

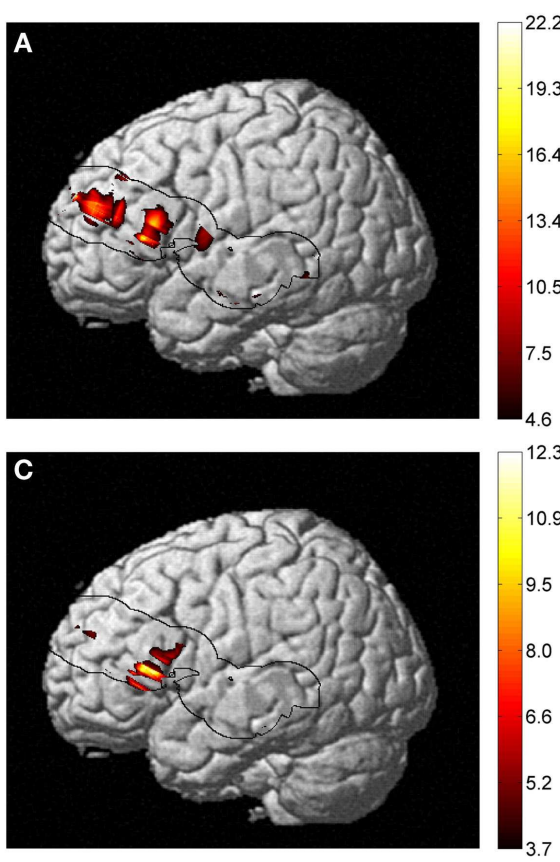

FIGURE 7 | Results of a two-way ANOVA on [HbR] examining the factors of age and condition (of lexical-semantic task) on the activation maps. (A) Main effect of age, (B) main effect of condition, (C) interaction between age and condition, and (D) effect of age on pseudo-word processing are
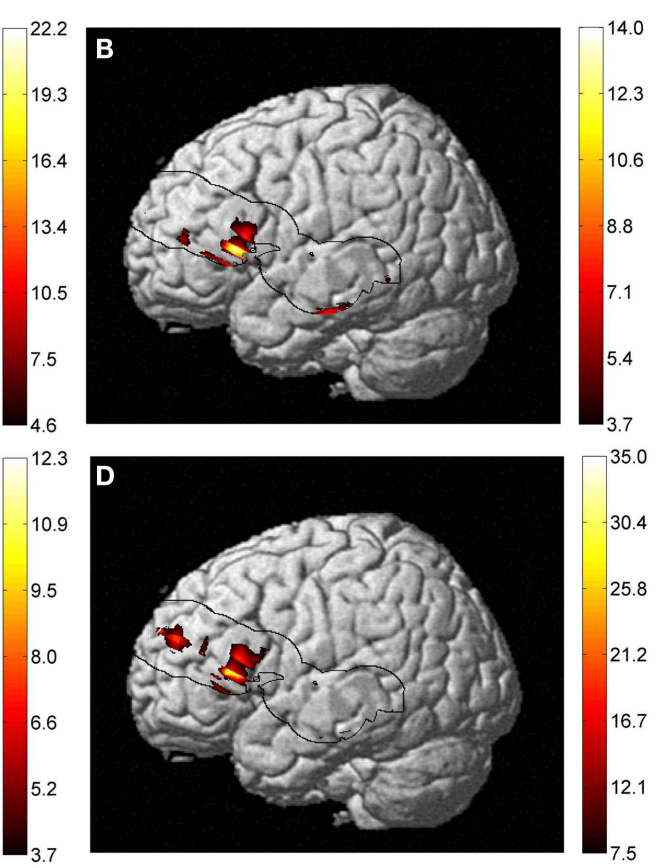

shown. An IFG age difference was present in all four types of analysis but with different extents of activation. A post hoc analysis revealed an effect of age on pseudo-word processing in the DLPFC and IFG. No significant $\left[\mathrm{HbO}_{2}\right]$ or $[\mathrm{HbT}]$ differences were observed.

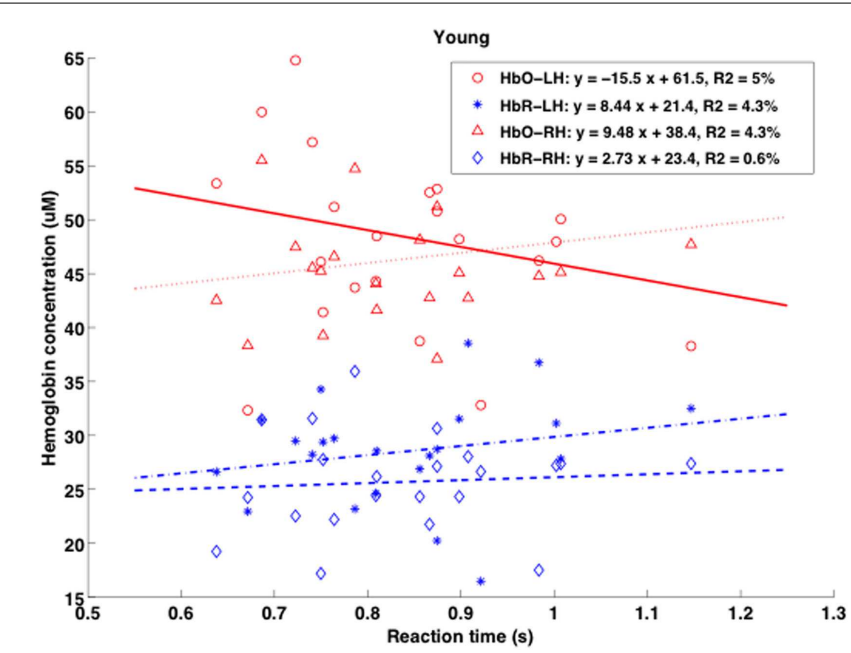

FIGURE 8 | Scatterplots of mean RT ( $x$-axis, in seconds) vs. TRS baseline physiology measures (absolute [HbR] and [HbO]; $y$-axis, in micromolar) for the younger and elderly groups are shown for both right and left

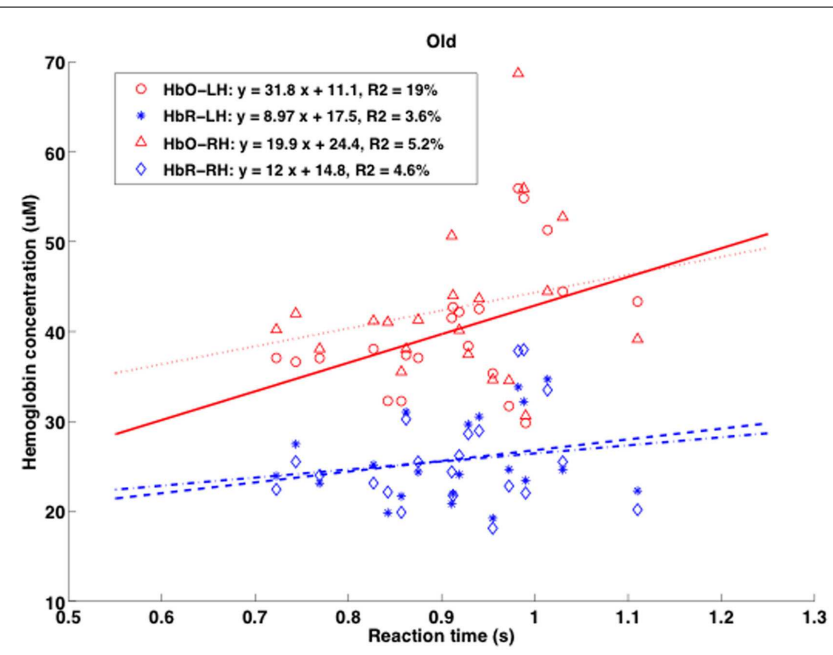

hemispheres (RH and LH). Pearson's $r$ coefficients showed no significant correlation between baseline $[\mathrm{Hb}]$ and $\mathrm{RT}$, but different trends were present when comparing age groups. word form area (55)]; activation in the elderly cohort is compatible with the idea that bilateral neural activity increases with age (56, 57), although it is important to note that this age-related pattern of activity was observed by means of $\Delta[\mathrm{HbR}]$ differences in the frontotemporal cortex and $\left[\mathrm{HbO}_{2}\right]$ variation in the DLPFC. Without $[\mathrm{HbT}]$ variation and $\Delta[\mathrm{HbR}]$ differences, it could be assumed that this latter observation is due to mere neural activity and not to baseline physiological differences.

In the contrast between pseudo-words and real words, we found an age-different cluster of activation in the right IFG-STG intersection, bilateral DLPFC, and left IFG, which is consistent with previous findings claiming for the compensatory mechanism of 
the brain activity with effort in accordance with the behavioral finding that RTs are longer for pseudo-words $(56,58)$. It can be noted that the hemispheric laterality for language is relative and that it relies on a stronger engagement of the left hemisphere for syntactic and semantic processing, which nevertheless coexists with right-hemisphere activation. Thus, when the different age groups are compared, the difference in hemispheric patterns of activation could express over-recruitment of reserve networks, meaning that activation becomes less lateralized. Moreover, controlling for the baseline physiology strengthened the analyses, as it revealed differences in mere neural activity triggered by the task and not in the absolute hemoglobin concentration differences (data shown in TRS results). However, a question remains about whether bilateral frontal activity in older adults is driven by task difficulty per se or whether baseline physiological differences compared to their younger counterparts led to this differentiation.

The inverted hemodynamic response in the young group could be due to local coarse regulation of oxidative metabolism, provoked by the increase in neuronal activity, which is overwhelmed by an increase in CBF. In this regard, Woolsey and colleagues (59) postulated that there is a hemodynamic "steal" effect. The "steal phenomenon" may explain this observation by accounting for subsequent CBF changes: some arterioles were metabolically dilated while others in neighboring areas were constricted $(60,61)$.

More generally speaking, this study confirms the usefulness and sensitivity of hemodynamic-based corrected fNIRS imaging in investigating the neurofunctional reorganization of word processing and cognition with age. The same technique could be used after brain lesion and in recovery. This study also confirms the existence of a form of neurofunctional reorganization that corresponds to compensatory mechanisms, allowing for the preservation of linguistic abilities despite the neurophysiological changes present in aging.

In summary, while the combination of absolute and relative changes in hemoglobin concentration eliminates some of the assumptions previously required in NIRS data analysis, further improvements are needed. Future studies will be augmented by parallel ASL measurements of blood flow variation during brain activation, to provide a detailed measurement of quantitative events accompanying neuronal activation. Individual brain volume analyses would also provide a better estimation of the optimal source-detector distances for different age groups. In the case of atrophy in the elderly population, it is important to correct for the source-detector distances to allow for optimum light penetration and differences in light scattering and absorption.

\section{ACKNOWLEDGMENTS}

This research was supported by grants from the Canadian Institutes of Health Research MOP-93542 to Yves Joanette and Bernadette Ska and IOP-118608 to Yves Joanette, and through collaboration with the École Polytechnique de Montréal, Department of Biomedical Engineering. The authors would like to thank Dr. Louis Bherer for providing full access to NIRS equipment and auxiliary physiological measurement devices. We are grateful to Jean-Sébastien Provost for the neuropsychological assessments.

\section{REFERENCES}

1. Cohen JE. Human Population: the next half century. Science (2003) 302(5648):1172-5. doi:10.1126/science. 1088665

2. Ferri CP, Prince M, Brayne C, Brodaty H, Fratiglioni L, Ganguli M, et al. Global prevalence of dementia: a Delphi consensus study. Lancet (2005) 366(9503):2112-7. doi:10.1016/S0140-6736(05)67889-0

3. Craik FIM, Salthouse TA. The Handbook of Aging and Cognition. New York: Routledge (2000).

4. Raz N, Lindenberger U, Rodrigue KM, Kennedy KM, Head D, Williamson A, et al. Regional brain changes in aging healthy adults: general trends, individual differences and modifiers. Cereb Cortex (2005) 15(11):1676-89. doi:10.1093/ cercor/bhi044

5. Grady CL, Springer MV, Hongwanishkul D, McIntosh AR, Winocur G. Agerelated changes in brain activity across the adult lifespan. J Cogn Neurosci (2006) 18:227-41. doi:10.1162/089892906775783705

6. Cabeza R. Hemispheric asymmetry reduction in older adults: the HAROLD model. Psychol Aging (2002) 17(1):85-100. doi:10.1037/0882-7974.17.1.85

7. Bookheimer S. Functional MRI of language: new approaches to understanding the cortical organization of semantic processing. Annu Rev Neurosci (2002) 25:151-88. doi:10.1146/annurev.neuro.25.112701.142946

8. Démonet J-F, Thierry G, Cardebat D. Renewal of the neurophysiology of language: functional neuroimaging. Physiol Rev (2005) 85(1):49-95. doi:10.1152/ physrev.00049.2003

9. Mummery CJ, Patterson K, Hodges JR, Price CJ. Functional neuroanatomy of the semantic system: divisible by what? J Cogn Neurosci (1998) 10(6):766-77. doi:10.1162/089892998563059

10. Thompson-Schill SL, D'Esposito M, Aguirre GK, Farah MJ. Role of left inferior prefrontal cortex in retrieval of semantic knowledge: a reevaluation. Proc Natl Acad Sci U S A (1997) 94(26):14792-7. doi:10.1073/pnas.94.26.14792

11. Hedden T, Gabrieli JDE. Insights into the ageing mind: a view from cognitive neuroscience. Nat Rev Neurosci (2004) 5(2):87-96. doi:10.1038/nrn1323

12. Raz N, Rodrigue KM. Differential aging of the brain: patterns, cognitive correlates and modifiers. Neurosci Biobehav Rev (2006) 30(6):730-48. doi:10.1016/j. neubiorev.2006.07.001

13. Lu H, Xu F, Rodrigue KM, Kennedy KM, Cheng Y, Flicker B, et al. Alterations in cerebral metabolic rate and blood supply across the adult lifespan. Cereb Cortex (2011) 21(6):1426-34. doi:10.1093/cercor/bhq224

14. Bäckman L, Dixon RA. Psychological compensation: a theoretical framework. Psychol Bull (1992) 112(2):259-83. doi:10.1037/0033-2909.112.2.259

15. Hertzog C. An individual differences perspective: implications for cognitive research in gerontology. Res Aging (1985) 7(1):7-45. doi:10.1177/ 0164027585007001002

16. Stern Y. The concept of cognitive reserve: a catalyst for research. J Clin Exp Neuropsychol (2003) 25(5):589-93. doi:10.1076/jcen.25.5.589.14571

17. D'Esposito M, Deouell LY, Gazzaley A. Alterations in the BOLD fMRI signal with ageing and disease: a challenge for neuroimaging. Nat Rev Neurosci (2003) 4(11):863-72. doi:10.1038/nrn1246

18. Hutchison JL, Lu H, Rypma B. Neural mechanisms of age-related slowing: the $\delta \mathrm{CBF} / \delta \mathrm{CMRO} 2$ ratio mediates age-differences in bold signal and human performance. Cereb Cortex (2012) 23(10):2337-46. doi:10.1093/cercor/bhs233

19. Hutchison JL, Shokri-Kojori E, Lu H, Rypma B. A BOLD perspective on agerelated neurometabolic-flow coupling and neural efficiency changes in human visual cortex. Front Psychol (2013) 4. doi:10.3389/fpsyg.2013.00244

20. Wong EC, Buxton RB, Frank LR. Implementation of quantitative perfusion imaging techniques for functional brain mapping using pulsed arterial spin labeling. NMR Biomed (1997) 10(4-5):237-49. doi:10.1002/(SICI)10991492(199706/08)10:4/5<237::AID-NBM475>3.0.CO;2-X

21. Grady CL. Cognitive neuroscience of aging. Ann N Y Acad Sci (2008) 1124(1):127-44. doi:10.1196/annals.1440.009

22. Ansaldo AI, Kahlaoui K, Joanette Y. Functional near-infrared spectroscopy: looking at the brain and language mystery from a different angle. Brain Lang (2012) 121(2):77-8. doi:10.1016/j.bandl.2012.03.001

23. Delpy DT, Cope M, van der Zee P, Arridge S, Wray S, Wyatt J. Estimation of optical pathlength through tissue from direct time of flight measurement. Phys Med Biol (1988) 33(12):1433-42. doi:10.1088/0031-9155/33/12/008

24. Villringer A, Planck J, Hock C, Schleinkofer L, Dirnagl U. Near infrared spectroscopy (NIRS): a new tool to study hemodynamic changes during activation of brain function in human adults. Neurosci Lett (1993) 154(1-2):101-4. doi:10.1016/0304-3940(93)90181-J 
25. Buxton RB, Uludag K, Dubowitz DJ, Liu TT. Modeling the hemodynamic response to brain activation. Neuroimage (2004) 23(Suppl 1):S220-33. doi:10. 1016/j.neuroimage.2004.07.013

26. Fox PT, Raichle ME. Focal physiological uncoupling of cerebral blood flow and oxidative metabolism during somatosensory stimulation in human subjects. Proc Natl Acad Sci U S A (1986) 83(4):1140-4. doi:10.1073/pnas.83.4.1140

27. Hoge RD, Franceschini MA, Covolan RJM, Huppert T, Mandeville JB, Boas DA. Simultaneous recording of task-induced changes in blood oxygenation, volume, and flow using diffuse optical imaging and arterial spin-labeling MRI. Neuroimage (2005) 25(3):701-7. doi:10.1016/j.neuroimage.2004.12.032

28. Hoge RD, Pike GB. Oxidative metabolism and the detection of neuronal activation via imaging. J Chem Neuroanat (2001) 22(1-2):43-52. doi:10.1016/S08910618(01)00114-4

29. Hyder F, Kida I, Behar KL, Kennan RP, Maciejewski PK, Rothman DL. Quantitative functional imaging of the brain: towards mapping neuronal activity by BOLD fMRI. NMR Biomed (2001) 14(7-8):413-31. doi:10.1002/ nbm.733

30. Ances BM, Liang CL, Leontiev O, Perthen JE, Fleisher AS, Lansing AE, et al. Effects of aging on cerebral blood flow, oxygen metabolism, and blood oxygenation level dependent responses to visual stimulation. Hum Brain Mapp (2009) 30(4):1120-32. doi:10.1002/hbm.20574

31. Bonnéry C, Leclerc P-O, Desjardins M, Hoge R, Bherer L, Pouliot P, et al. Changes in diffusion path length with old age in diffuse optical tomography. J Biomed Opt (2012) 17(5):056002. doi:10.1117/1.JBO.17.5.056002

32. Duncan A, Meek JH, Clemence M, Elwell CE, Fallon P, Tyszczuk L, et al. Measurement of cranial optical path length as a function of age using phase resolved near infrared spectroscopy. Pediatr Res (1996) 39(5):889-94. doi:10.1203/00006450199605000-00025

33. De Rigal J, Escoffier C, Querleux B, Faivre B, Agache P, Lévêque J-L. Assessment of aging of the human skin by in vivo ultrasonic imaging. I Invest Dermatol (1989) 93(5):621-5. doi:10.1111/1523-1747.ep12319741

34. Gagnon L, Gauthier C, Hoge RD, Lesage F, Selb J, Boas DA. Double-layer estimation of intra- and extracerebral hemoglobin concentration with a time-resolved system. J Biomed Opt (2008) 13(5):054019. doi:10.1117/1.2982524

35. Plassman BL, Langa KM, Fisher GG, Heeringa SG, Weir DR, Ofstedal MB, et al. Prevalence of dementia in the United States: the aging, demographics, and memory study. Neuroepidemiology (2007) 29(1-2):125-32. doi:10.1159/000109998

36. Knecht S, Dräger B, Deppe M, Bobe L, Lohmann H, Flöel A, et al. Handedness and hemispheric language dominance in healthy humans. Brain (2000) 123(12):2512-8. doi:10.1093/brain/123.12.2512

37. Oldfield RC. The assessment and analysis of handedness: the Edinburgh inventory. Neuropsychologia (1971) 9(1):97-113. doi:10.1016/0028-3932(71)90067-4

38. Chen Y, Parrish TB. Caffeine's effects on cerebrovascular reactivity and coupling between cerebral blood flow and oxygen metabolism. Neuroimage (2009) 44(3):647-52. doi:10.1016/j.neuroimage.2008.09.057

39. Perthen JE, Lansing AE, Liau J, Liu TT, Buxton RB. Caffeine-induced uncoupling of cerebral blood flow and oxygen metabolism: a calibrated BOLD fMRI study. Neuroimage (2008) 40(1):237-47. doi:10.1016/j.neuroimage.2007.10.049

40. Reitan R. The Halstead-Reitan Neuropsychological Test Battery: Theory and Clinical Interpretation. Tucson Ariz: Neuropsychology Press (1985).

41. Nasreddine ZS, Phillips NA, Bédirian V, Charbonneau S, Whitehead V, Collin I, et al. The montreal cognitive assessment, MoCA: a brief screening tool for mild cognitive impairment. J Am Geriatr Soc (2005) 53(4):695-9. doi:10.1111/ j.1532-5415.2005.53221.x

42. Axelrod BN. Validity of the Wechsler abbreviated scale of intelligence and other very short forms of estimating intellectual functioning. Assessment (2002) 9(1):17-23. doi:10.1177/1073191102009001003

43. Schrimsher GW, O’Bryant SE, O’Jile JR, Sutker PB. Comparison of tetradic WAIS-III short forms in predicting full scale IQ Scores in neuropsychiatric clinic settings. J Psychopathol Behav Assess (2007) 30(3):235-40. doi:10.1007/s10862007-9066-9

44. Wechsler D. WMS-R: échelle clinique de mémoire de Wechsler-Révisée: manuel. Ed. rev. Paris: Ctre Psychologie Appliq (1991).

45. Balota DA, Cortese MJ, Sergent-Marshall SD, Spieler DH, Yap MJ. Visual word recognition of single-syllable words. J Exp Psychol Gen (2004) 133(2):283-316. doi:10.1037/0096-3445.133.2.283

46. New B, Ferrand L, Pallier C, Brysbaert M. Reexamining the word length effect in visual word recognition: new evidence from the English Lexicon Project. Psychon Bull Rev (2006) 13(1):45-52. doi:10.3758/BF03193811
47. Friston KJ, Holmes AP, Worsley KJ, Poline J-P, Frith CD, Frackowiak RSJ. Statistical parametric maps in functional imaging: a general linear approach. Hum Brain Mapp (1994) 2(4):189-210. doi:10.1002/hbm.460020402

48. Luh WM, Wong EC, Bandettini PA, Hyde JS. QUIPSS II with thin-slice TI1 periodic saturation: a method for improving accuracy of quantitative perfusion imaging using pulsed arterial spin labeling. Magn Reson Med (1999) 41(6):1246-54. doi:10.1002/(SICI)1522-2594(199906)41:6<1246::AIDMRM22>3.0.CO;2-N

49. Buxton RB, Wong EC, Frank LR. Dynamics of blood flow and oxygenation changes during brain activation: the balloon model. Magn Reson Med (1998) 39(6):855-64. doi:10.1002/mrm.1910390602

50. Friston KJ, Ashburner JT, Kiebel SJ, Nichols TE, Penny WD. Statistical Parametric Mapping: The Analysis of Functional Brain Images. 1st ed. Academic Press (2006). Available from: http://www.amazon.co.uk/Statistical-Parametric-MappingAnalysis-Functional/dp/0123725607/ref=pd_bbs_sr_1/203-4612468-8457523? ie $=\mathrm{UTF} 8 \&$ s $=$ books\&qid $=1177328758 \&$ sr $=8-1$

51. Ye JC, Tak S, Jang KE, Jung J, Jang J. NIRS-SPM: statistical parametric mapping for near-infrared spectroscopy. Neuroimage (2009) 44(2):428-47. doi:10.1016/ j.neuroimage.2008.08.036

52. Wong EC, Buxton RB, Frank LR. Implementation of quantitative perfusion imaging techniques for functional brain mapping using pulsed arterial spin labeling. NMR Biomed (1997) 10(4-5):237-49.

53. Herscovitch P, Raichle ME. What is the correct value for the brain-blood partition coefficient for water? J Cereb Blood Flow Metab (1985) 5(1):65-9. doi:10.1038/jcbfm.1985.9

54. Grabowski TJ, Damasio H, Tranel D, Ponto LLB, Hichwa RD, Damasio AR. A role for left temporal pole in the retrieval of words for unique entities. Hum Brain Mapp (2001) 13(4):199-212. doi:10.1002/hbm.1033

55. McCandliss BD, Cohen L, Dehaene S. The visual word form area: expertise for reading in the fusiform gyrus. Trends Cogn Sci (2003) 7(7):293-9. doi:10.1016/S1364-6613(03)00134-7

56. Donnelly KM, Allendorfer JB, Szaflarski JP. Right hemispheric participation in semantic decision improves performance. Brain Res (2011) 1419:105-16. doi:10.1016/j.brainres.2011.08.065

57. Van Ettinger-Veenstra H, Ragnehed M, McAllister A, Lundberg P, Engström M. Right-hemispheric cortical contributions to language ability in healthy adults. Brain Lang (2012) 120(3):395-400. doi:10.1016/j.bandl.2011.10.002

58. Binder JR, McKiernan KA, Parsons ME, Westbury CF, Possing ET, Kaufman JN, et al. Neural correlates of lexical access during visual word recognition. J Cogn Neurosci (2003) 15(3):372-93. doi:10.1162/089892903321593108

59. Woolsey TA, Rovainen CM, Cox SB, Henegar MH, Liang GE, Liu D, et al. Neuronal units linked to microvascular modules in cerebral cortex: response elements for imaging the brain. Cereb Cortex (1996) 6(5):647-60. doi:10.1093/ cercor/6.5.647

60. Ances BM. Coupling of changes in cerebral blood flow with neural activity: what must initially dip must come back up. J Cereb Blood Flow Metab (2004) 24(1):1-6. doi:10.1097/01.WCB.0000103920.96801.12

61. Harel N, Lee S-P, Nagaoka T, Kim D-S, Kim S-G. Origin of negative blood oxygenation level-dependent fMRI signals. J Cereb Blood Flow Metab (2002) 22(8):908-17. doi:10.1097/00004647-200208000-00002

Conflict of Interest Statement: The authors declare that the research was conducted in the absence of any commercial or financial relationships that could be construed as a potential conflict of interest.

Received: 28 July 2014; accepted: 12 November 2014; published online: 01 December 2014.

Citation: Amiri M, Pouliot P, Bonnéry C, Leclerc P-O, Desjardins $M$, Lesage F and Joanette $Y$ (2014) An exploration of the effect of hemodynamic changes due to normal aging on the fNIRS response to semantic processing of words. Front. Neurol. 5:249. doi: 10.3389/fneur.2014.00249

This article was submitted to Brain Imaging Methods, a section of the journal Frontiers in Neurology.

Copyright () 2014 Amiri, Pouliot, Bonnéry, Leclerc, Desjardins, Lesage and Joanette. This is an open-access article distributed under the terms of the Creative Commons Attribution License (CC BY). The use, distribution or reproduction in other forums is permitted, provided the original author(s) or licensor are credited and that the original publication in this journal is cited, in accordance with accepted academic practice. No use, distribution or reproduction is permitted which does not comply with these terms. 